\title{
The Association of Geoscientists for International Development (AGID)
}

\section{http://agid.igc.usp.br}

The Association of Geoscientists for International Development (AGID) is a non-governmental organisation, affiliated to IUGS, that was founded in 1974 by a small group of international geoscientists who shared a common interest in the application of geoscience to development issues in the so-called 'developing countries', populated by many of the poorest members of the world community. The aims of the organisation were clearly stated as follows:

- To encourage communication between all individuals, societies, agencies and corporations interested in the application of the geosciences to international development.

- To encourage and promote activities in geoscientific fields which are related to the needs of developing countries.

- To promote and encourage among geoscientists a lively awareness of their responsibilities in the management of natural resources.

- To emphasise to those countries co-operating in international aid programmes the fundamental role of the geosciences in social and economic development.

- To encourage personal contact and the creation of research links between members in different countries.

This was, and remains, an ambitious set of objectives and it is worth reviewing here how AGID has attempted to achieve its aims during the period since its inception almost thirty years ago.

To date AGID has either initiated, organised or co-sponsored over two hundred and twenty individual projects, predominantly in the form of seminars or workshops with the aim of transferring knowledge or sharing experience concerning a wide range of development issues. Of particular importance amongst these have been the fifty geoscience writing workshops which have resulted in the training of over twelve hundred geoscientists in developing countries thereby making a significant contribution to the aim of facilitating communication between geoscientists in the developing and developed world. Also concerned with improved communication have been the eighty-two editions of the Association's journal, Geoscience and Development, originally launched as 'AGID News'. Like the IUGS journal, Episodes, the AGID journal reaches many readers in developing countries whose libraries cannot afford to subscribe to the many commercial scientific journals currently available. During the same period, twenty books on subjects ranging from mineral exploration techniques to urban geology, groundwater and geohazards have been published though demand was such that most are now out of print. AGID also publishes the 'South and West Asia Newsletter' for circulation in that region.

The above theme of knowledge transfer has been further developed by AGID Canada, a registered charity, through its book and journal exchange scheme which coordinates the collection of technical and geoscientific literature, including books, journals and maps, and distribution of this material to educational and research institutions in the developing world. Through this scheme thousands of books and journals have been supplied to libraries in developing countries. Assistance has also been granted to over one hundred and twenty postgraduate students in the form of AGID's William Greenwood Scholarships, which provide a financial contribution towards meeting the cost of necessary fieldwork.

Throughout this period, funding has come from various sources. For more than twenty years the Canadian Government,

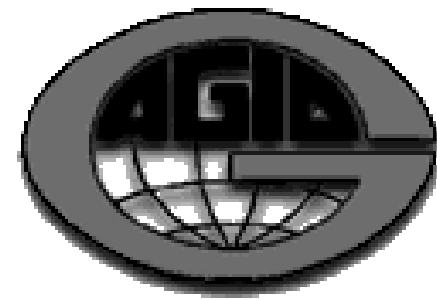

through the Canadian International Development Agency, provided core funding that enabled AGID to sustain most of the operations outlined above. IUGS, the United Kingdom Department for International Development, and UNESCO have also supported a variety of activities. Core funding has largely been used to provide 'seed money' to initiate projects which have then usually succeeded in attracting further sponsorship from elsewhere. Hitherto membership dues have provided only a small part of the funds necessary to maintain AGID's operations and dues have been kept at a low level, especially for members from the developing world. As a consequence of the cessation of core funding from CIDA in 1995, AGID has had to reduce its activities and is currently reviewing its aims for the future in the light of the current situation for geosciences in development.

Thirty years ago, when AGID was founded, that much overused and often misused term 'sustainable development' had yet to enter the everyday vocabulary of those involved in international aid. Now it is an essential element of any aid document and at the same time an awareness of the relevance of geoscience to many aid projects, and the profilation of NGO's, both large and small, working in the environmental and resource sectors, has radically changed the world in which AGID seeks to operate. This has happened to the extent that AGID has had to address the question as to whether the time has come either for it to wind up its operations and retire gracefully from the international scene or to continue, albeit with a changed structure that is able to respond more readily to global change. Consultations with members, currently underway, suggest that the latter view is likely to find majority support. Proposals are being prepared to place before the membership plans for a much more decentralised structure with responsibility for activities devolved to regional councils which will also be responsible for forging closer links with likeminded organisations within their regions. Whether or not this approach succeeds in sustaining AGID's efforts for geoscience and development in the future, will depend on the enthusiastic participation of our members and the support of potential sponsors. AGID will have succeeded if it finally decides to cease operations because its aims have largely been fulfilled rather than through a loss of belief in such aims.

The links with IUGS have always been important to AGID and the International Geological Congress is an important element in the AGID calendar. Not only does AGID hold its General Assembly during the IGC but AGID is normally co-convenor of several sessions during IGC, and the 2004 IGC will be no exception. In this connection we are pleased to see the increased efforts that are being made to increase the proportion of registrants from developing countries. Hopefully the next IGC, in Florence, will see a successful debate of AGID's aims in the presence of a greatly increased number of delegates from the developing world.

\author{
Dr A J Reedman \\ Secretary/Treasurer \\ Association of Geoscientists for International Development \\ E-mail: antony@areedman.freeserve.co.uk
}

